CITATION: Esparza, A., Sosa, R. \& Connor, A.M. (2017) The shape of firms: opportunities from rapid manufacturing. Paper presented at the EAI International Conference on Technology, Innovation, Entrepreneurship and Education

\title{
The Shape of Firms: Opportunities from Rapid Manufacturing
}

\author{
Antonio Esparza, Ricardo Sosa, and Andy M. Connor \\ Colab, Auckland University of Technology, Private Bag 92006 Wellesley Street, \\ Auckland 1142, New Zealand \\ \{rpf4932, ricardo.sosa, andrew. connor\} eaut.ac.nz
}

\begin{abstract}
This paper examines the role of design in the creation of new firms. A new interpretation of firm design is developed to explain the dynamics of entrepreneurship. This paper seeks to expand the conversation between design and management studies by focusing on the concept of shaping the firm. The study of the shape of the firm seeks to characterise the dependencies between the features of products and the organizational possibilities of new firms. We intersect theories from the fields of management and design theory to examine the shape of the firm in the entrepreneurship context. From this study, opportunities are identified for research approaches to address the entanglement between the shape of the product and the shape of the firm. Implications for practice are discussed.
\end{abstract}

Keywords: Firm Design, Entrepreneurship, Digital Technologies.

\section{Introduction}

The role of design in the creation of new business ventures has been documented in the academic and professional literature $[1,2,3]$. An alternative design approach to entrepreneurship considers it as a matter of firm design $[4,5]$, a process of creation of artificial means that negotiate with the environment. We suggest that more nuanced descriptions of firm design are needed. This paper frames the study of the shape of the firm based on the intersection of design science, entrepreneurship theories, and rapid manufacturing technology. First, we examine the roles of design in the creation of new business ventures and describe shape as the formal dimension of firm design. We then examine theories of firm creation applying an ontology of design activity, the Function-Behaviour-Structure (FBS) framework, to elucidate a space for the shape of the firm. The relationships between the shape of the product and the shape of the firm are analysed. Finally, we formulate a set of questions for the study of this entanglement in new business creation to empower future entrepreneurs to identify and capitalise on these relationships. 


\section{Expanding Design \& Management}

Entrepreneurship theories are strongly influenced by assumptions in management studies about the purpose, object, and process of creating business ventures. Two strands of thought are represented in the role of design in entrepreneurship: Strategic Design (SD) and Design Thinking (DT). SD is a branch of strategic thinking concerned with the creation of idealised plans for the optimal accomplishment of objectives. SD is distinguished for generating a carefully controlled process of thought, centralizing planning in the figure of the strategist, simplifying an original, complete, and explicit outcome, separated from the implementation process $[6,7]$. DT for strategic planning has gained popularity as a tool for integrating divergent (synthetic) and convergent (analytic) reasoning. DT is mainly used for the synthesis of solutions based on abductive logic, the exploitation of opportunities, and the use of inquiry for value generation $[8,9]$. It is the intention of this proposition to expand the definition and applicability of design principles in management based on the study of design activity.

Design has been defined as the capacity of "conceiving, planning, and making products that serve human beings in the accomplishment of their individual and collective purposes" $[10,11]$. In other words, design is a process that uses the creation of artefacts to interact with the environment and effectuate desired results. Designed artefacts create new practices and as a consequence new identities of those who use $[12,13,14]$. As an activity of creation of our desired future state, the scope of design covers the production of all human artefacts, such as firms, from very diverse perspectives different from SD and DT.

Understanding firms as products of their products, designs can be understood as first-order principles of [15]. Therefore through design, managers are in charge of creating value within the firm in order to achieve differentiation. This view aligns with Sarasvathy's perspective of entrepreneurship. Based on the study of expert entrepreneurs, she portrays the entrepreneurial process as the effectuation of negotiations that helps entrepreneurs in the achievement of their goals $[16,17]$. Specifically, she highlights the need to research the processing of language and the categorisation of symbols in the entrepreneurial [5]. The behaviours around artefacts related to the firm, such as brands, logos, products, etc. imply that the firm is an artefact that can be studied at a semantic level. Therefore, the study of design opens new opportunities for the study of the entrepreneurship process resulting in the design of a firm like an artefact.

\subsection{Artefacts of Design}

Artefacts are the object of design. In order to modify our environment, we interact with artefacts through their shape. Human ecologies, like other ecologies, are defined by the spaces or fluids that enable the movement of substances [18]. Medium and substances are separated by surfaces which have specific layouts that we call "shape". Shape configurations gather properties that help us distinguish them and give them a specific character i.e. room, chair, cloth, bank, or [19]. Through shape, artefacts relate within the semantic ecology of our environment, as illustrated in Figure 1a. Shape 
communicates the counter-ability of artefacts, or the available purposes and actions that we can perform with the artefact. Through shape, artefacts help us in the accomplishment of the objectives of their design, as illustrated in Figure 1b. When designing an artefact, designers refer to the perceptual grammar that resembles the possibilities of creation within a specific typology of artefacts.

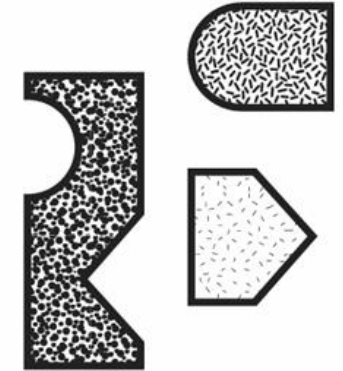

a. An ecology is composed by substances and a space or medium

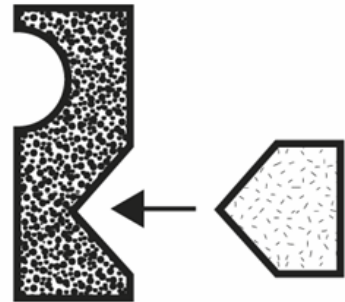

b. Shape limits the substance of the artefact and signals its counter-abilities or affordances (Gibson, 2014)

Fig. 1. Shape ecologies.

Due to the complexity of human production, the shape of system artefacts can be difficult to model. The creation of transactional systems lacks a formal manifestation compared with the design of physical artefacts. Therefore, the relationship between users, the environment, and firms as artefacts is not bounded by visible appearances, but by conditions of scale and reciprocity. Scale determines the span of interaction while reciprocity is the correspondence between the artefact and the user's interactive capabilities [20]. This is evident in the development of designed objects and spaces where the corresponding relationships between our bodies and the artefacts are found in the size of doors, or the roundness of handles. It is evident that in the case of complex systems such as firms, the scale and reciprocity shall be difficult to detect. We can infer that today in the design of business we experience a mismatch between the shape of the business and the relationship that it has to our human bodies and minds. When does our interaction with a business start and end? What are our expected behaviours? What is the vocabulary of the firm that we are meant to interpret?

Today the brand and its touch-points, as well as the product, and the packaging, are considered [21]. Nevertheless, a close examination of the existing theories of the firm suggests that the elements that compose a firm could be a designable as well. For instance, the theory of transaction costs considers that the firm will try to include all the transactions that increase the complexity of operations and as a result, increase cost. A model of the shape of the firm should attempt to account for these manifestations, and develop a designable perceptual grammar of the firm. 


\section{The Shape of the Firm and the Theories of the Firm}

Current descriptions of the firm suggest the relational nature of business enterprises. Usually they account for heterogeneous compositions of resources, knowledge and human capital. Nevertheless, the firm as an artefact must also be justified as an effectuative prosthetic of human bodies. Consequently, it must have a reciprocal relationship to our scales and perceptive boundaries. The shape of the firm needs to be designed to afford specific behaviours on users according to the business logic and objectives. Customers, partners, employees, entrepreneurs, managers, stakeholders, and other artefacts interact with the affordances that the shape of the firm presents. The firm may interface through symbols and systems (brands, products, etc.) to elicit the desired behaviours of the business strategy. Therefore, inasmuch as the term user extends to all the people that interact with the signifiers of the firm, the quality of a good or bad firm design could be defined not only for its relative performance, but by the difference between the expected behaviours of the design and the real behaviours that are elicited in users through these symbols. A different typology of firms based on shapes, could generate more options for business design and innovation creating more mechanisms for differentiation. However, in order to articulate a model of the shape of the firm, the existing theories that describe the composition of the firm space should be situated in design terms.

\subsection{The FBS Ontology and Framework}

The FBS ontology [22] is a useful to describe the design space and has been used extensively to model design $[23,24,25$. Its ontology organises design based on three fundamental constructs: Function, Behaviour, and Structure. Function is described as the teleological cause of the artefact, or the relationship between the goals and how they are met. Behaviour describes the performance derived from the artefact's structure. Structure refers to the arrangement of the artefact's components whether they are physical, virtual or social. Behaviour can be derived from structure using physical laws or heuristics, whilst no direct connection exists between function and [26]. The FBS framework splits the artefact space in two; the expected world, and the interpreted world. In the expected world, users and designers make up expectations of the artefact to be based on perception. Differently from users, designers enact this expectation in the design process. The interpretation world includes the artefact's use. Interpretation does not always aligns with expectation. An expected function (Fe) inductively derives an expected behaviour (Be) and an expected structure (Se). The materialised structure $(\mathrm{S})$ elicits a behaviour $(\mathrm{B})$ which in comparison with the design goals reveals a function (F). The FBS schema is depicted in Figure 2. The distance between these two processes expands the set of transformations from a linear transformation, to a set of iterative processes that reflect many design processes, from the generation of requirements to the interpreted description of the artefact. 


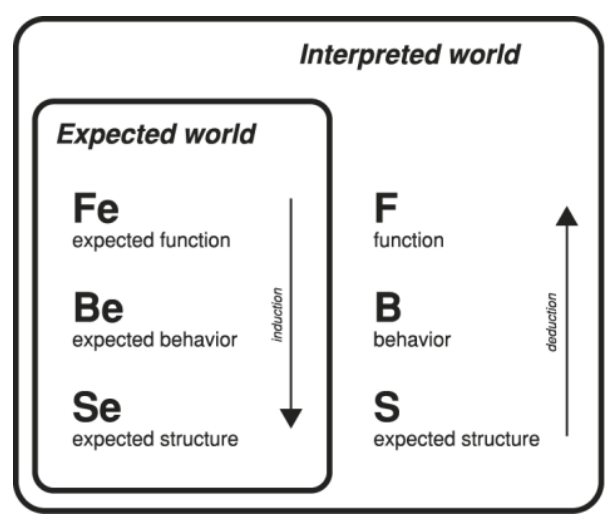

Fig. 2. The FBS framework supports a model of design processes [22]

\subsection{The FBS Ontology and Framework}

Three groups of theories that account for the nature of the firm in economic sciences can be situated within the FBS framework to yield a different understanding of the firm as an artefact. Firstly, the theories of the firm, which account for the purpose and nature of the firm against market structures. Next, the models of enterprise ontology, originated as a tool for representing the entities and activities related inside a business. And finally, the theory of business models which explains the logic that underlies value creation and delivery. While each of the groups is formed by multiple models and theories, we consider their shared features.

First, the theories of the firm can be considered as a group centred in the description of a meta-level of abstraction. The purpose of the theory of the firm is to define the formal relations that differentiate it from the market and industry structures in a way that contributes to the study of economics [27, 28, 29, 30, 31]. Consequently, the models that the theories of the firm supply, are strongly related to the expected function $(\mathrm{Fe})$ and behaviours $(\mathrm{Be})$ of the firm. Coase [28] makes evident the question of the firm purpose, i.e., "why is there any organisation?". Similarly, theories of the firm attempt "first, to specify the decisions that business firms will make (as a basis for more aggregate predictions of the economy) and second, to prescribe appropriate decision rules for a rational firm operating in a market economy" [32]. Overall, these theories seek to describe an ontology of the firm based on the observations of business, ergo showing interpretations of it as a phenomenon, not an artefact.

The majority of these theories account for functions that were based on the economic assumptions of supposed homogeneous goals of the entrepreneur and opportunism. In the design of new businesses, a tension is observable between the predefined layout of these expected functions and behaviours in economy, and the goals that individuals could bring to firm creation. Theories of creative entrepreneurship such as creative organizing [33] and bricolage [34] do not fit the theories of the firm. These theories do not show relationships that are able to induce structures and behaviours of the firm beyond the existing paradigms of economics and 
management. Moreover, the conflict between supposed heterogeneous goals and behaviours evidences a void in the theories of the firm that if addressed could create more possibilities for firm design.

Despite being a detailed reference of business entities, enterprise ontologies fail to map the firm onto a structural level. The diversity of models around enterprise ontologies can differ but they all concur in the representation of the entities to be monitored in order to exercise control of the company. Fox \& Gruninger stress the role of ontologies in the integration of the enterprise by the addition of subsets of specific ontologies; "for example, the notion of manufacturability requires reasoning about the product's properties, preconditions, and effects of activities and the capabilities of resources" [35]. Therefore, business ontologies seem to be a reference tool for performance accountability rather than representing the structure itself. Yet, as legal litigations show, not all the affordable behaviours through the firm are accounted by business [36]. Therefore, if we consider that design theories of artefacts recognise the interpretation of the user in the redefinition of the purpose and its interaction with the context in the creation of affordances, an enterprise ontology mistakes the role of human entities in the exercise of creativity and innovation.

Business models show the logic behind the operation and profitability of a firm [37]. Research and popular literature consider that the design of a business model is essential in the early stages of the entrepreneurial process. Situating the business model definition within the FBS framework, the business logic fits the expected behaviour (Be) around the designed artefact. The activity based design process of business models proposed by Zott \& Amit portraits the business model as a blueprint for the derivation of the firm structure [38]. Accordingly, Osterwalder and Pigneur situate the business model as an organising matrix inside the firm. They argue that the interaction between the business model, strategy, information, and organisation guides the firm's operation. The manifested business model of a company becomes a tool for the communication of strategy [39]. Hence, it could expand itself from the expected, to the interpreted behaviour since it elicits specific actions (at least at a macro level) in the exercise of the firm. Nevertheless, since there is no object to refer as a firm artefact, the deduced behaviours can be forced through explicit strategy and could be understood as ambiguous.

The resulting mapping of theories of the firm, enterprise ontologies and business models in to the FBS framework is shown in Figure 3. 


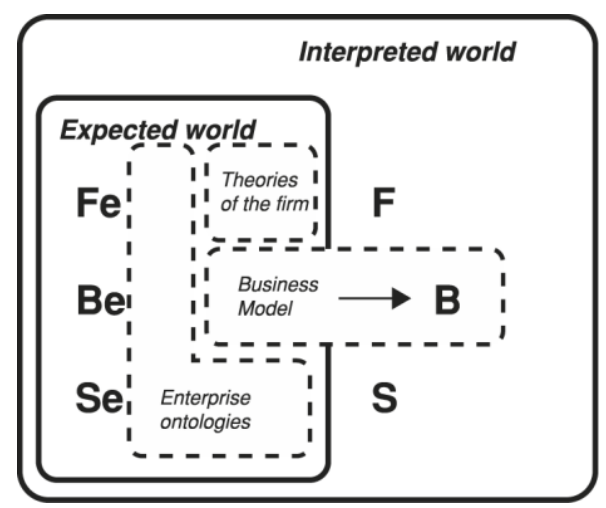

Fig. 3. The existing theories that describe firms only consider one "natural" firm structure that is pushed to the interpreted world through strategic communication.

\subsection{The Entangled Shape of the Firm}

The theories of design and management examined here show the extant need for defining the interpreted world of the firm artefact. Literature on product architecture has interesting developments that consider the interaction between the firm and its users. Based on evidence of the relationship between product architecture and the success of firms, these studies confirm that the division of labour in firms reflects the principle of bounded rationality and consequently mirrors the configuration of the product into the information processing structures of the firm [40, 41]. As a consequence, the arrangement of the product architecture can affect the organisational learning curve and the exercise of authority between organisational divisions [42]. This mirroring process suggests that the development of information mechanisms that support product architecture solidifies and extends through time beyond the firm and into its suppliers and the rest of the industry [43]. Different products predefine available organisational configurations regardless the imposed strategy. The inadequate mirroring of a product architecture in the early stages of business development may carry associative thinking biases that need to be tackled through iterations of divergent configurations of the product and value proposition [44, 45]. The mirroring effect implies that one of the most important strategic choices in firm creation is the relationship between the components in product architecture.

As Sarasvathy proposes, entrepreneurship can be considered as the design of a firm artefact that aids entrepreneurs in the fulfilment of their goals. In the design of the firm artefact, a range of participants as users are acknowledged: Customers, suppliers, employees, etc. Consequently, possible misinterpretations of individual roles inside corporations need to be considered. Errors in the use of an artefact, such as pulling a door when it needs to be pushed, or walking over "lines of desire" in gardens and parks instead of going around the corner, are design flaws. Similarly, behaviours like delayed payments, product order misunderstandings, quality issues, and fraudulent practices, could be caused by affordances in the firm that are not accounted for. Moreover, desired behaviours focused on the creation of value and innovation could 
also be elicited through the design of the shape of the firm.Based on the mirroring process between product and organisational architectures, the main argument of this proposition is that the shape of the firm is composed by the dependencies between functional components in product architecture and organisational configurations which evoke the behaviours of firms users. Therefore, in the firm design process, the conceptualisation of different dependencies in the shape of the firm will make available specific product and organisational possibilities that can be matched to the goals of the entrepreneur. This approach is different from conventional innovation and entrepreneurial processes which create a product, and force an expected behaviour of users through strategic communication. Hence, current tools operate under the assumptions of the theories of the firm, business models and enterprise ontologies, regardless different product architectures. This new approach opens new opportunities for the creation of methods and tools that articulate the shape of the firm according to its interaction with humans, and other artefacts (logos, brands, media, other firms, etc.).

Just as the guidelines in the shape of a chair artefact, the dependencies between components and teams resemble the shape of the firm artefact (Figure 4a). Traditional entrepreneurship takes the design of a product and enforces organisational behaviours through strategy (Figure $4 \mathrm{~b}$ ). Through the design of the shape of the firm, product architectures can be purposefully selected that correspond to organizational configurations (Figure 4c).

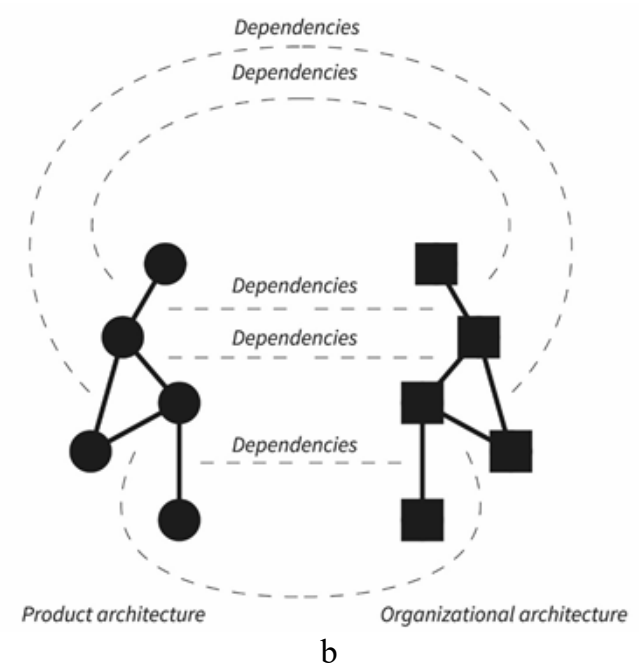

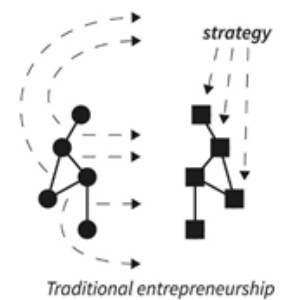

a

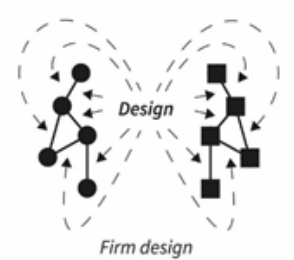

c

Fig. 4. Mappings of dependencies between product and firm design.

\subsection{Rapid Manufacturing in the Shape of the Firm}

This proposition is especially relevant today in view of digital technologies. Information Technology based tools summarize in code structures that before 
required the commitment of valuable resources. As a result, firms today are more flexible than before [46]. Tools that now are used for around the business model, such as enterprise application, customer relationship management, and computer aided design software can be modified to fit and interact with the shape of the firm to bring out desired behaviours in users and feedback relevant data for the iteration of the shape itself. Tools for data science, such as mining and analytics can help in the shaping of the affordable relationships in the geometry of the firm. With the involvement of data, generative algorithms of design could be used to adopt a flexible strategy that take advantage of contingencies and react instantly to social and market fluctuations. Technologies like additive manufacturing (AM) could project this digital flexibility to the production of material goods. Algorithms of generative design, can adapt the shape of produced products to the desired affordances of the shape in real time. Manufacturing of goods can be as flexible as needed for the business to effectuate the acquisition of partnerships and resources.
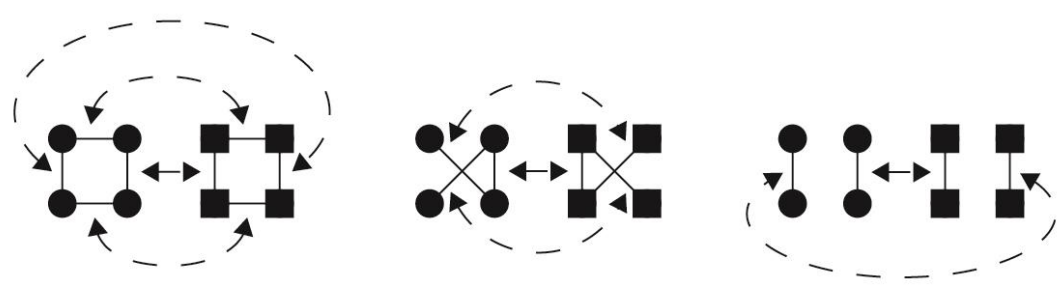

Fig. 5. Additive manufacturing could enable the exploration of different shape configurations without heavy capital investment.

For entrepreneurship this is an opportunity to leverage the relationships and shape the firm through the initial product according to the final goal of the entrepreneur. This will expand the role of design and the available control of the entrepreneur over the firm's future. Traditionally, regardless the industry, entrepreneurship processes are conformed by a discovery, evaluation, and exploitation of the business idea [47]. By integrating digital technologies, this processes have become more agile in the implementation and evaluation of explored ideas. Nevertheless, this processes guides itself through trial and [48, 49]. A model of the shape of the firm could inform the implementation of this experiments in a more purposeful and specific way. It would integrate strategy to the production of the goods immediately in a way that is particular to the product that is being fabricated. Therefore, strategy could use digital technologies to extremely detail and micro-manage the shape of the firm. Unique paths for differentiation could originate in the interaction between the entrepreneurial contingency and the project that could push the competitiveness of small firms in front of competing corporations.

Experimentation with alternative concepts of digital business can be brought forward thanks to a model of the shape of the firm. While companies usually rely on the same structure, different shapes of firms could experiment with concepts that current ones find very expensive to use. That is the case of distributed manufacturing, a model where automated manufacturing like $3 \mathrm{D}$ printing could fabricate goods in 
smaller facilities distributed geographically. Despite the potential saves in cost, research has proven to be difficult to [50]. A specialized design of the shape of a firm could leverage the creation of networks that make this model possible. Other explorations with cryptocurrencies or "money of the commons" could also be matched to shapes of firms. Shapes that facilitate stakeholder governance mechanisms could make use of such technologies to foster social entrepreneurship.

\section{Conclusion}

Expanding the idea of firm design beyond the creation of instruments for strategy (SD \& DT) to firm design creates a vast space for the exploration of the firm as a designable artefact. Artefacts as prosthetics of human bodies help us modify our environment to match our desired goals. Likewise, a firm artefact would help the entrepreneur to effectuate the contingencies that surround the project and fulfil specific purposes. After an analysis of current theories of firm creation, this paper identifies a void between the expected behaviours of the firms and the interpreted behaviours inside it. There seems to be no guided action outside the communication of strategy and as a consequence, the existing theories do not account for all the afforded behaviours in the interaction between the firm and its possible users. Based on the evidence from studies on product architecture, we propose that the shape of the firm can be found in the dependencies between the product and organizational architectures. Therefore, by designing a specific set of dependencies, the product and organizational architectures of the firm could be mutually defined.

The study of the shape of the firm brings together the study of entrepreneurship and design. Processes of entrepreneurship could make use of design to articulate different shapes according to specific goals attainable by the entrepreneur. Tools for creative entrepreneurship could be designed to take advantage of the distinctive conditions of each entrepreneurial context. This would help grounding popular tools like business modelling on the entrepreneur's reality and give more certainty to projects that do not have access to venture capital or even information technology means. Shifting focus to technology based entrepreneuring, a theory of the shape of the firm would give a very valuable resource for start-ups to adapt and react based on the integration of data feeds to the design process of the firm.

This study also identifies opportunities for the study of the perceptive grammar and the resulting typologies of firms. Different types shall be classified according to size, industries, products, value propositions etc. Dependencies of the firm could be also classified according to their function. Making use of analogical reasoning from biology theory, the main dependencies for the growth and reproduction of the firm could be theorised. Start-ups could be designed to act as dynamically as viruses, or rely on high memory and learning capacity like elephants and insect colonies. Industries could be studied according to the interactions within firms, viewed as ecosystems. Firms could be designed to create relationships of competition by cultivating dependencies that tie them to strong yet flexible networks of firms and users. Extending the analogy, firm and product differentiation can be achieved based 
on strategies of lifespans, replication, ecological inheritance, niche construction, and mutual adaptation [51] (Sterelny 2004).

This paper closes with three areas of interest for original research around the aesthetics of firm-artefact relations. First, the role of the product needs to be studied in the context of the evolution of the firm structure in the entrepreneurial process. This will permit the representation of the dependencies between the two structures in a practical context. Second, different shapes of firms need to be explored with the aid of rapid manufacturing technologies. Just as we can explore the shape of product design, we must explore a language that represents accurately the entanglement of the architectures and the guidelines of the shape as a whole. As mentioned before, rapid manufacturing technologies are notable for their flexibility. Therefore, by making changes in product architecture using additive manufacturing, it would be reasonable to expect to induce the dependencies and map the families of firm design. Finally, expanding the research around product architecture, the development of cases that analyse the interaction of firm shapes such as the failure between Boston Dynamics \& Google [52], the adoption of Snapchat features by Facebook apps [53], or new product development in game consoles [54]. By considering these three possible routes of inquiry, the study of the shape of the firm has the potential to leverage design in the creation of more deliberate futures for entrepreneurs and new businesses.

\section{References}

1. T. Brown, "Design Thinking," Harvard Business Review, 01-Jun-2008. [Online]. Available: https://hbr.org/2008/06/design-thinking. [Accessed: 29-Mar-2016].

2. L. Kimbell, "Rethinking Design Thinking: Part I," Des. Cult., vol. 3, no. 3, pp. 285-306, Nov. 2011.

3. R. L. Martin, Design of Business: Why Design Thinking is the Next Competitive Advantage. Harvard Business Press, 2009.

4. S. D. Sarasvathy, "Entrepreneurship as a science of the artificial," J. Econ. Psychol., vol. 24, no. 2, pp. 203-220, Feb. 2003

5. S. D. Sarasvathy, "Making It Happen: Beyond Theories of the Firm to Theories of Firm Design," Entrep. Theory Pract., vol. 28, no. 6, pp. 519-531, Dec. 2004.

6. H. Mintzberg, "The design school: Reconsidering the basic premises of strategic management," Strateg. Manag. J., vol. 11, no. 3, pp. 171-195, Mar. 1990.

7. H. Mintzberg and J. A. Waters, "Of strategies, deliberate and emergent," Strateg. Manag. J., vol. 6, no. 3, pp. 257-272, Jul. 1985.

8. J. Liedtka, "In Defense of Strategy as Design," Calif. Manage. Rev., vol. 42, no. 3, pp. 830, Spring 2000.

9. R. Martin, "Design thinking: achieving insights via the "knowledge funnel," Strategy Leadersh., vol. 38, no. 2, pp. 37-41, 2010.

10. R. Buchanan, "Design Research and the New Learning," Des. Issues, vol. 17, no. 4, 2001.

11. H. A. Simon, The Sciences of the Artificial. MIT Press, 1996.

12. M. Heidegger and J. Stambaugh, Being and time; : a translation of Sein und Zeit. Albany, NY : State University of New York Press, [1996], 1996.

13. K. Krippendorff, The semantic turn: a new foundation for design. Boca Raton: CRC/Taylor \& Francis, 2006 
14. V. Margolin, "Design, the Future and the Human Spirit," Des. Issues, vol. 23, no. 3, pp. 415, Jun. 2007.

15. A. Dong, M. Kleinsmann, and D. Snelders, "A Design-based Theory of the Firm," Unpublished, 2017.

16. S. D. Sarasvathy, "Causation and Effectuation: Toward a Theoretical Shift from Economic Inevitability to Entrepreneurial Contingency," Acad. Manage. Rev., vol. 26, no. 2, pp. $243-$ 263, Apr. 2001.

17. S. D. Sarasvathy, Effectuation: elements of entrepreneurial expertise. Cheltenham, Glos, UK ; Northampton, MA: Edward Elgar, 2008.

18. J. J. Gibson, The Ecological Approach to Visual Perception: Classic Edition. Psychology Press, 2014.

19. F. Martín Juez, Contribuciones para una antropología del diseño, 1. ed. Barcelona: Gedisa Editorial, 2002.

20. M. Krampen, "Semiotics in Architecture and Industrial/Product Design," Des. Issues, vol. 5, no. 2, pp. 124-140, 1989.

21. E. R. Abbing and C. van Gessel, "Brand-Driven Innovation," Des. Manag. Rev., vol. 19, no. 3, pp. 51-58, Summer 2008.

22. J. S. Gero and U. Kannengiesser, "The Function-Behaviour-Structure Ontology of Design," in An Anthology of Theories and Models of Design, A. Chakrabarti and L. T. M. Blessing, Eds. Springer London, 2014, pp. 263-283.

23. G. Cascini, G. Fantoni, and F. Montagna, "Situating needs and requirements in the FBS framework," Des. Stud., vol. 34, no. 5, pp. 636-662, Sep. 2013.

24. K. Dorst and P. E. Vermaas, "John Gero's Function-Behaviour-Structure model of designing: a critical analysis," Res. Eng. Des., vol. 16, no. 1-2, pp. 17-26, Nov. 2005.

25. U. Kannengiesser and J. S. Gero, "A Process Framework of Affordances in Design,” Des. Issues, vol. 28, no. 1, pp. 50-62, Dec. 2011.

26. L. Qian and J. S. Gero, "Function-behavior-structure paths and their role in analogy-based design," AI EDAM, vol. 10, no. 4, pp. 289-312, Sep. 1996.

27. J. B. Barney, “The Resource-Based Theory of the Firm," Organ. Sci., vol. 7, no. 5, pp. 469469, Oct. 1996.

28. R. H. Coase, "The Nature of the Firm," Economica, vol. 4, no. 16, pp. 386-405, Nov. 1937.

29. R. M. Grant, "Toward a knowledge-based theory of the firm," Strateg. Manag. J., vol. 17, no. S2, pp. 109-122, Dec. 1996.

30. O. D. Hart, "Incomplete Contracts and the Theory of the Firm," J. Law Econ. Organ., vol. 4, no. 1, pp. 119-139, 1988.

31. O. E. Williamson, "Chapter 3 Transaction cost economics," vol. 1, B.-H. of I. Organization, Ed. Elsevier, 1989, pp. 135-182.

32. R. M. Cyert, E. A. Feigenbaum, and J. G. March, "Models in a behavioral theory of the firm," Behav. Sci., vol. 4, no. 2, pp. 81-95, Apr. 1959.

33. B. Johannisson, "Towards a practice theory of entrepreneuring," Small Bus. Econ., vol. 36, no. 2 , pp. $135-150$, Feb. 2011.

34. T. Baker and R. E. Nelson, "Creating Something from Nothing: Resource Construction through Entrepreneurial Bricolage," Adm. Sci. Q., vol. 50, no. 3, pp. 329-366, Sep. 2005.

35. M. S. Fox and M. Gruninger, "Enterprise Modeling," AI Mag., vol. 19, no. 3, p. 109, Sep. 1998.

36. K. Hoerr, "Uber driver jailed for raping woman," ABC News, 13-Jun-2017. [Online]. Available: http://www.abc.net.au/news/2017-06-13/sydney-uber-driver-jailed-over-rape-ofpassenger-kings-cross/8612936. [Accessed: 30-Jun-2017].

37. A. Osterwalder, Y. Pigneur, and C. L. Tucci, "Clarifying Business Models: Origins, Present, and Future of the Concept," Commun. Assoc. Inf. Syst., vol. 16, no. 1, Jul. 2005.

38. C. Zott and R. Amit, "Business Model Design: An Activity System Perspective," Long Range Plann., vol. 43, no. 2-3, pp. 216-226, Apr. 2010. 
39. A. Osterwalder, "HE BUSINESS MODEL ONTOLOGY A PROPOSITION IN A DESIGN SCIENCE APPROACH," UNIVERSITE DE LAUSANNE ECOLE DES HAUTES ETUDES COMMERCIALES, 2004.

40. P. Anderson and M. L. Tushman, "Technological Discontinuities and Dominant Designs: A Cyclical Model of Technological Change," Adm. Sci. Q., vol. 35, no. 4, p. 604, Dec. 1990.

41. R. M. Henderson and K. B. Clark, "Architectural Innovation: The Reconfiguration of Existing Product Technologies and the Failure of Established Firms," Adm. Sci. Q., vol. 35, no. 1, p. 9, Mar. 1990.

42. R. Sanchez and J. T. Mahoney, "Modularity, flexibility, and knowledge management in product and organization design," Strateg. Manag. J., vol. 17, no. S2, pp. 63-76, Dec. 1996.

43. L. J. Colfer and C. Y. Baldwin, "The mirroring hypothesis: theory, evidence, and exceptions," Ind. Corp. Change, vol. 25, no. 5, pp. 709-738, Oct. 2016.

44. C. Christensen, The Innovator's Dilemma: When New Technologies Cause Great Firms to Fail. Harvard Business Review Press, 2013.

45. N. Furr, J. A. Nickerson, and R. Wuebker, "A Theory of Entrepreneuring," Social Science Research Network, Rochester, NY, SSRN Scholarly Paper ID 2747458, Mar. 2016.

46. P. Schubert, J. Fisher, and U. Leimstoll, "ICT and Innovation in Small Companies," ECIS 2007 Proc., Jan. 2007.

47. S. Shane and S. Venkataraman, "The Promise of Entrepreneurship as a Field of Research," Acad. Manage. Rev., vol. 25, no. 1, pp. 217-226, Jan. 2000.

48. E. Ries, The Lean Startup: How Today's Entrepreneurs Use Continuous Innovation to Create Radically Successful Businesses. Crown Publishing Group, 2011.

49. D. Sola, G. S. Borioli, and G. Scalabrini, "New Product Development and Disciplined Experimentation," Symphonya Emerg. Issues Manag., vol. 0, no. 2, pp. 105-118, Jul. 2015.

50. S. H. Khajavi, J. Partanen, and J. Holmström, "Additive manufacturing in the spare parts supply chain," Comput. Ind., vol. 65, no. 1, pp. 50-63, Jan. 2014.

51. K. Sterelny, Externalism, epistemic artefacts and the extended mind. The externalist challenge, pp. 239-254, 2004

52. A. Macfarlane, "Google sells maker of 'nightmare-inducing' robots to Japan's SoftBank," CNNMoney, 09-Jun-2017. [Online]. Available: http://money.cnn.com/2017/06/09/technology/boston-dynamics-robots-google-alphabetsoftbank/index.html. [Accessed: 30-Jun-2017].

53. A. Heath, "Here are all the times Facebook has copied Snapchat so far," Business Insider, 27-May-2017. [Online]. Available: http://www.businessinsider.com/all-the-timesfacebook-copied-snapchat-2017-5. [Accessed: 30-Jun-2017].

54. D. Thier, "Nintendo's Biggest Mobile Game Is The One Nobody's Really Talking About," Forbes, 30-May-2017. [Online]. Available: http://www.forbes.com/sites/davidthier/2017/05/30/nintendos-biggest-mobile-game-is-theone-nobodys-really-talking-about/. [Accessed: 30-Jun-2017]. 